\title{
Weber despedaçado: até quando dura a dominação carismática?: uma análise da política no Haiti*
}

\section{Weber shattered: how long does the charismatic authority? An analysis of policy in Haiti}

Renata de Melo Rosa ${ }^{1}$

\section{Resumo}

Este artigo tem como objetivo discutir o caráter transitório do tipo de dominação carismática proposta por Max Weber como um modelo de dominação que faria a articulação entre o tipo de dominação tradicional e a racional-legal. Embora levando em consideração que Weber trabalha com tipos ideais que não guardam correlação imediata com a realidade, cumpre neste artigo discutir a elasticidade política da dominação carismática no contexto haitiano que, ao longo de 200 anos tem apresentado esta dominação como o único tipo ideal disponível para acessar o poder no Haiti. O objetivo de reflexão teórica deste ensaio é aprofundar os estudos sobre a dominação carismática como estruturante de cenários políticos considerados frágeis. Existiria nexo causal entre "falência do Estado" e predominância do tipo de dominação carismática? Se assim for, como quantificar o caráter transitório deste tipo de dominação?

Palavras-chave: Carisma. Haiti. Transição política. Tipos de dominação

\begin{abstract}
This article aims to question the transitory quality of charismatic leadership proposed by Max Weber as a model of authority that would make the link between the traditional authority and rational-legal. Although Weber works with ideal types which have no immediate correlation with reality, we must discuss how long would be the charismatic leadership in the Haitian context that, throughout its political history has shown the charismatic authority as the only possible way to access to power. The goal of this essay is to discuss the charismatic leadership as the growing of several policy scenarios considered fragile. Is there a causal link between "state failure" and the predominance of the charismatic leadership? If so, how to think about the transitory of this kind of authority that support Haiti policy for two centuries?
\end{abstract}

Keywords: Charisma. Haiti. Political. Ttransition. Authority

Recebido em 14.09.2012

Aprovado em 10.11.2012

1 Pós-Doutorado em Relações Internacionais; Coordenadora do curso de Relações Internacionais do UniCEUB; Líder do Núcleo de Estudos de Diplomacia Responsável. Email: renata. rosa@uniceub.br. 


\section{Introdução}

Um dos desafios centrais para o Haiti contemporâneo é construir uma transição política que seja capaz de trazer de instaurar a ordem racional-legal para o país. Apesar de oficialmente o Estado haitiano haver completado mais de dois séculos de existência, a fragmentação política acompanha o processo de formação do Estado, ele mesmo gestado de forma fragmentada ${ }^{2}$. Para entender de forma cautelosa as razões da fragmentação política, das divisões internas e da "soberania compartilhada" (WOODWARD, 2005) vivida na contemporaneidade por meio das inúmeras Missões de Paz aprovadas pelas Nações Unidas, este artigo procura discutir a permanência do modelo de dominação carismática no Haiti como parte da lógica da cultura haitiana, avessa à ocidentalização e a um processo de instituição da dominação racional-legal. Nos termos conceituais weberianos, o carisma específico de vários políticos que acederam ao poder se rotinizou, mas não fez com que este modelo de dominação se desgastasse. Em algumas vezes, como no caso de Papa e Baby Doc (1957-1986), a dominação carismática de Françoise Duvalier retrocedeu ao modelo de dominação tradicional, fazendo com que a dominação que deveria ser transitória (WEBER, 1994, p. 161) se inclinasse para o tipo “carismático-hereditária (WEBER, 1994, p. 174), já que

2 Após a morte do presidente Jean Jacques Dessalines, em 1806, o Haiti se fragmenta politicamente e se divide entre o Reino do Norte, liderado por Henri Christophe e o Reino do Sul, liderado por Alexandre Pétion. (CASIMIR, 2009).

\section{A trajetória do carisma}

Não há como analisar a história política dos últimos 25 anos sem levar em consideração a figura de Jean Bertrand Aristide, razão pela qual faremos em seguida uma breve análise detida acerca de sua gravitação ao poder, tendo em vista que somados os golpes de Estado sofridos e apesar de ter sido eleito duas vezes uma legitimamente (1991) e outra de forma bastante controversa $\left(2000^{3}\right)$, Aristide nunca conseguiu completar seus mandatos presidenciais. As causas destas rupturas sistemáticas, bem como a importância política deste líder para a transição política no Haiti serão problematizadas nas páginas subseqüentes.

Jean Bertrand Aristide nasceu em Port Salut, em 1953. Em sua auto-biografia intitulada "Tout moun se moun” (ARISTIDE, 1995), apropriou-se do provérbio popular haitiano que afirma que "toda pessoa é uma pessoa"4. Nesta obra, Aristide se auto-concebe como caudatário de um socialismo rural praticado em Port Salut, dentro do qual não se conhecia a miséria, mas uma solidariedade das populações rurais haitianas. Aristide mudou-se ainda criança para Porto Príncipe e encontrou na Igreja Católica e no sacerdócio um caminho para proseguir a educação formal. Desde os discursos por liberdade política proferidos nas varias paróquias em que foi responsável, das lutas de oposição à ditadura dos Duvalier até sua eleição como presidente, Aristide despertou bastante desconforto na Cúpula da Igreja Católica haitiana, que acabou, após inúmeros pedidos de licença, expulsando-o, por razões de indisciplina (ARISTIDE, 1995) e fazendo com que suas "qualidade sobrenaturais" (WEBER, 1994, p. 195) se tornassem ainda mais marcantes.

3 Eleições não reconhecidas pela OEA e pela União Europeia.

4 Nas palavras de Jean Casimir (2009, p. 101), "no Haiti, "toda pessoa é uma pessoa" (tout moun se moun) e toda pessoa é um "negro". Ser negro no Haiti é condição anterior ao conceito de pessoa. No entanto, esta definição não se relaciona e nem exclui indivíduos pela cor da pele. Ser negro no Haiti é pertencer. Só pertence ao Haiti quem se enquadra nesta categoria, que exige muito mais do indivíduo que apenas ter a pele escura. Exige modos de vida não-ocidentais, expressar-se em kreyòl e viver no Haiti. Segundo Casimir, tout moun se moun é um provérbio que representa uma das invariantes da cultura haitiana. Não é uma frase qualquer, mas um principio valorativo fundamental em uma cosmovisão radicalmente igualitaria da vida social, um postulado fundamental que explica o proceso dialético da histórica política e social haitiana. 
A transição política que Aristide encabeça foi profundamente importante para que o Haiti iniciasse o proceso de transição política que Max Weber classificou de passagem de um tipo de dominação tradicional (ditadura dos Duvalier, com características de poder hereditário e poderes absolutos conferidos à familia, embora oriunda de um poder carismático) para a dominação racional legal, baseada em obediência aos estatutos (WEBER, 1994). O próprio Aristide entendeu que a sua eleição seria a $2^{\mathrm{a}}$. Independência do Haiti. As suas palavras para definir a sua eleição em 1991 foram as seguintes:

Segunda independência, proclamada nesse 7 de fevereiro de 1991! Devia pois ter havido a primeira. Quase dois séculos antes, um homem de ascendência igualmente excepcional, Toussaint-Louverture, inspirava a primeira independência de um povo de escravos. 1804! Napoleão, todo poderoso, coroado imperador nesse mesmo ano em Paris, não podía contrariar a emancipação coletiva de uma nação de negros. A ruptura de hoje é a mesma que a do princípio do século XIX (ARISTIDE, 1995, p. 23)

O potencial de ruptura de dominação tradicional, liderada pelos Duvalier de 1957 a 1986, com caráter carismático, despótico e absolutista (DIEDERICH; AL BURT, 1969) era notável. O modelo teórico de Weber (1994), evolutivo no que tange às sucessões dos tipos de dominação parecia tomar forma com a ascensão deste líder de carisma incontestável. No entanto, o modelo ideal de sucessão das dominações encontrou dificuldades para fechar ciclos na história política de transições no Haiti. A importância do surgimento no Haiti de um líder carismático, como Aristide, que rompe com a dominação tradicional dos Duvalier e ascende ao poder de forma democrática é paradgmática em termos conceituais de transição das dominações, já que, de acordo com Weber, "a dominação carismática, como algo extraordinário, opõe-se estritamente tanto à dominação racional, especialmente a burocrática, quanto à tradicional [...] a [dominação] carismática derruba o pasado e, nesse sentido, é especificamente revolucionária (WEBER, 1994, p. 160).

O problema teórico incide quando Weber argumenta que da dominação carismática podem derivar o "burocratismo" ou a dominação carismático-hereditária, com traços de dominação tradicional) (WEBER, 1994, p. 174). O potencial revolucionário é ameaçado no momento em que o carisma se rotiniza e o líder carismático luta para se manter no poder, seja por meio de sua própria pessoa, pelo "carisma-hereditário", ou pela instauração da burocracia. Qualquer que seja a opção política de um líder de carisma rotinizado em relação a seu futuro político, cria tensões de legitimidade no seio da sociedade civil que, dependendo de sua situação econômica e maturidade política, pode seguir novos líderes carismáticos ou se adequar à burocracia.

O fato de Aristide não haver conseguido implementar a dominação racional-legal se deve a muitas variáveis políticas. Minha hipótese é que o fato de haver sofrido um golpe após sete meses de mandato (de fevereiro a setembro de 1991) alterou significativamente a percepção de controle de poder planejada por Aristide. Ademais, o tempo de espera que o presidente vivenciou para retornar ao seu posto (de 1991 a 1994) rompeu com a potencialidade de seu mandato de transformar o Haiti em um espaço político democrático. Soma-se a isso a fragilidade dos mecanismos de cooperação política da comunidade internacional, tanto regional, coordenado pela Organização dos Estados Americanos, como mundial, liderado pelo Conselho de Segurança das Nações Unidas em oferecer respostas rápidas e eficazes de condenação ao golpe de estado empunhado pelo General Raoul Cédras ao presidente Aristide, em 1991. O aborto precoce da força política do carisma trouxe consequências importantes para o Haiti, insolúveis do ponto de vista da conciliação nacional e que obrigou o Conselho de Segurança das Nações Unidas a aprovar 4 Missões no período de sete $\operatorname{anos}^{5}$ (1993-2000). Em 2000, com a reeleição de Aristide, seu carisma começa a dar sinais visíveis de deterioração. Sem estrutura administrativa, seu carisma era uma força frágil e a um passo da rotinização. De acordo com Pierre Charles,

regressando do exílio com um amplo apoio da
população e sustentação ilimitada da comuni-
dade internacional, o ex-padre de St-Jean Bosco
mostrou sua impotência em fazer bom uso dos
imensos recursos de que podia dispor. Efetiva-
mente, a comunidade internacional havia ofer-
tado uma soma de aproximadamente US\$ 2 bi-
lhões, em empréstimos e doações. Esse montante
esperava que os projetos apropriados para ser
posto à disposição do governo e da população.
A má gestão comprometeu essa possibilidade de
recuperar a economia e de garantir o êxito de um
projeto que havia suscitado tanta esperança nos
meios populares. Ao mesmo tempo, no plano
político, em vez de se abrir e atrair outras catego-

\footnotetext{
5 São elas: UNMIH (1993 a 1996); UNSMIH (1996 a 1997); UNTMIH (1997); MIPONUH (1997-2000).
} 
rias sociais, o regime retomou sua linha demagógica e populista, recorrendo mais e mais à força.

A continuidade desse poder havia sido assumida por René Préval, que o sucedeu, jogando plenamente no papel de marionete. Cumprindo à risca os desígnios de seu tutor, continuou sua política de violação dos direitos humanos, de nepotismo, e todo um jogo maquiavélico destinado a garantir-lhe o regresso. (PIERRE CHARLES, 2004, p.)

Frente ao desgaste político e sob suspeita em relação a seu caráter extracotidiano, os métodos populistas de Aristide começaram a emergir fortemente e sem sucesso. Na visão de Smarth,

O governo não formou um corpo administrativo. Muito acima das estruturas estava o presidente que criticava seus ministros publicamente e chegava inclusive a se declarar em oposição a seu próprio poder. Havia poucas preocupações pela institucionalidade democrática. O Executivo resistiu ao controle do Parlamento e o primeiro ministro respondeu às convocatórias do Parlamento, com manifestações de massa e com ameaças aos parlamentares. Cabe ressaltar que isso seria uma forte característica da forma de governar do presidente Aristide: a de tentar resolver os conflitos de poder fora dos canais institucionais e via mobilização das massas. Nesse marco, a oposição política e as forças sociais que não estavam de acordo com o governo nunca se sentiram em segurança. Em vez de acalmar o ambiente, Aristide se dedicou a esquentá-lo. Já as mudanças que fez nas Forças Armadas no mesmo dia de sua chegada ao poder eram preocupantes, sendo o general Abraham, o então Chefe das Forças Armadas, um homem conhecido por seu equilíbrio. Do General Cèdras3, sabia-se muito pouco, mas dizia-se que o homem passou a se mostrar partidário do novo chefe de Estado. Em síntese, com inimigos tão fortes como a burguesia, as forças armadas e os norte-americanos, Aristide deveria buscar novas alianças e acalmar o jogo em sua chegada ao poder. O apoio somente das classes populares e subalternas se mostraria bastante insuficiente. No fundo, as condições para um golpe de estado estavam bem presentes. (SMARTH, 2010, p. 179)

As consequências de um golpe de Estado no momento de um proceso de transição política são incalculáveis e certamente pesam no retrocesso à volta dos mecanismos tradicionais de dominação. Após o exílio em Caracas e Washington, a volta de Aristide ao Haiti foi garantida por 20 mil soldados americanos, em setembro de 1994 (SMARTH, 2010, p. 181). No entanto, Aristide volta diferente, desencantado, "americanizado", não volta como Titid, mas como Harry Stid (SMARTH, 2010), tamanho o proceso de ocidentalização que teve de pasar para ga- rantir sua volta ao poder ${ }^{6}$. Rompe por si mesmo as amarras simbólicas que o autorizavam a ser o líder político da comunidade haitiana que voluntariamente lhe conferiam legitimidade para o exercício do poder.

A fragilidade institucional compõe a natureza da dominação carismática, diria Weber (1994). Não tem quadro administrativo, não cria raízes institucionais e se manisfesta tanto pela ruptura da lógica de dominação tradicional quanto pela inauguração da dominação racional-legal. É grande, pois, a responsabilidade do líder carismático porque precisa enfrentar forças políticas poderosas que sustentam a lógica tradicional de funcionamento da política e ao mesmo tempo precisa implementar ações de gestão política baseadas na radicalização do princípio igualitário, na imparcialidade e na crença nos estatutos. Trata-se de uma missão politicamente improvável para a natureza que origina o poder carismático.

Se levarmos em consideração algo que talvez Weber não tenha nos advertido, que é a correlação de forças políticas internas de um país e a intervenção estrangeira, como é o caso do Haiti, a dominação carismática necessite de um estudo teórico mais detalhado a partir de sua existência permanente (e não transitória) no cenário político haitiano. Se o sentido da ação política dado pelo próprio agente da ação construir nexos analíticos mais sólidos para a compreensão de uma realidade multidimensional e multifacetada, como é dos cenários políticos contemporâneos, esta dimensão da vida política precisa ser estudada a fundo, como o que se propõe neste ensaio.

\section{Desafiando Weber: a lógica da organização social haitiana e a lógica do mundo ociden- tal: ser nèg no Haiti}

O pressuposto central desta reflexão refere-se ao fato de a lógica de organização do mundo ocidental e o modelo de política baseada nos pressupostos da dominação racional-legal, a saber: a "crença na legitimidade das ordens estatuídas e do direito de mando daqueles que, em virtude dessas ordens estão nomeados para exercer a dominação" (WEBER, 1994. p. 141) não repousar no lugar em que os haitianos conferem sentido aos acontecimentos da vida. Categorias "ordem impessoal, objetiva

\footnotetext{
6 Vale dizer que o período de 1991 a 1994 Aristide viveu nos Estados Unidos, em Washington.
} 
e legalmente instituída" (WEBER, 1994, p. 141), constroem uma pálida conexão com o modo de vida estruturado pelos "filhos renegados do Ocidente". Talvez incida aí o motivo pelo qual o Haiti não tenha "conseguido" cooperar de forma decisiva com os projetos de desenvolvimento elaborados pela comunidade internacional há, pelo menos 100 anos $^{8}$, quase todos baseados em uma crença profunda no 1) valor da competência, 2) de um exercício contínuo vinculado a determinadas regras (WEBER, 1994, p. 142) democracia, 3) "organização das instâncias fixas de controle e supervisão para cada autoridade institucional, com direito de apelação ou reclamação das subordinadas às superiores" (WEBER, 1994, p. 145).

A condição de existência de cada haitiano como ser social e ser político depende de um conjunto de variáveis interconectadas por sentidos simbólicos de pertença à comunidade nacional. Com tantas condicionalidades, pertencer à nação haitiana é um exercício diário de anti-comprometimento cultural com o Ocidente ou com os valores ocidentais. Para se opor a esta categoria fundante, existem os "Blanc", estrangeiros (THOMAZ, 2010), independentemente da cor e haitianos ocidentalizados, que vivem dentro ou fora do Haiti. A passagem da categoria "nèg" para "Blanc" é comum (o inverso também) e a variável que vai determinar a entrada em uma ou outra categoria é a afinidade pública demonstrada por cada haitiano ao Ocidente. "Blanc" não pertence à nação, não fala como "moun/pessoa", carrega na sua identidade a pecha da subordinação, da não inteligência (pa lespri) e tem chances muito remotas de atingir algum ponto sensível de cooperação entre os haitianos. A tensão entre "nègs" e "blancs" é a principal força política que move a adesão ou rejeição dos líderes políticos haitianos em seus projetos de ascensão ao poder. Entender como funciona esta lógica me parece central para a eficácia da transição da dominação carismática para a racional-legal.

\section{Nèg e política}

Para a construção de uma carreira política sustentável no Haiti, a condição primeira é ser um "nèg", como

\footnotetext{
7 Esta expressão está inscrita no Preâmbulo da Constituição Haitiana de 1805 apud Mirlande Manigat. "Los Derechos Humanos en la Constitución de 1987”. In: TEJEDA, Eddy. El Derecho a una vida digna. Santo Domingo - R/D: FLACSO, 2001.

8 A contar da intervenção norte-americana de 1915.
}

em todas as áreas da vida social haitiana. O principal reconhecimento público deste título é ter seu nome público transformado, geralmente evocado no diminutivo ou com adjetivos que indicam uma proximidade familiar notável (komé, kompé, papa, baby, ti), Por exemplo, René Préval é ti René, Jean Bertrand Aristide foi Titid, François Duvalier foi Papa Doc, Jean Claude Duvalier foi Baby Doc, Charles Henry Baker é Charlito Baker, etc. (PONGNON, 2010). Esta é uma condição sensível que precisa de compromissos e afirmações simbólicas constantes e a porta de acesso para o surgimento de líderes carismáticos. Apenas para ilustrar, Charles Baker é um político haitiano branco e Leslie Manigat é um político negro, só que neste caso, não existem dúvidas quanto ao fato de Charlito ser um "nèg" e Manigat ser visto como um blanc. O que os diferencia é o grau de afinidade com o Ocidente que os dois compartilham. Enquanto Charlito faz seus discursos em kreyòl, Manigat se expressa exclusivamente em francês, é um intelectual de linguagem sofisticada, o que, no imaginário haitiano, representa um laço mais ou menos indestrutível com o Ocidente e, portanto não pode pertencer à comunidade de valores haitiana. Outro provérbio importante no Haiti e que exclui da comunidade negros haitianos ocidentalizados francófonos é Pale franse pa lespri (falar francês não é inteligente) (CASIMIR, 2001).

A rotinização do carisma de Arisitide, nos termos de Max Weber (1994) se inicia neste momento e ele mesmo, ao sentir este desgaste e a possibilidade de deixar de ser "nèg" para ser "Blanc" preferiu atuar nos bastidores políticos de sua sucessão presidencial de 1996, apoiando a candidatura de René Préval (ti René). O ponto sensível foi para Aristide, a partir daquele momento, resgatar sua condição política inicial de pertencer à comunidade haitiana sem recair nenhuma dúvida a respeito de sua condição de nèg. É possível imaginar que esta condição nunca foi plenamente restaurada, o que nos faz supor que o cuidado na preservação da identidade nèg é o principal legado político dos haitianos, tendo em vista que a condição de pertença ao Haiti jamais pode ser abandonada. Tal entendimento foi particularmente válido para o Conselho Eleitoral Provisório (CEP) do Haiti ao não homologar a candidatura de Wyclef Jean, famoso cantor de rap, por não viver no Haiti. Vê-se aí que os critérios oficiais de nacionalidade formal não garantem acesso político aos privilégios dentro da comunidade haitiana. As alegações oficiais resumiram-se ao fato de Wyclef Jean não residir 
no país nos últimos cinco anos (METROPOLE HAITI, 2010). Desde o meu ponto de vista, Wyclef Jean, apesar de negro e oficialmente haitiano, ele não é um "nég” e portanto não "merece" compartilhar o universo de privilégios simbólicos e políticos. A força deste símbolo é determinante para a dinâmica de toda a vida social haitiana.

A visão de mundo dos "nég" é, portanto, antagônica e anti-dialética com o Ocidente, talvez antagônica e anti-dialética com o universo de regras impessoasis que estrutura a dominação racional-legal.

Partindo destas idéias, este texto propõe que as formas de dominação carismática, apesar de frágeis e transitórias, são para o cenário político haitiano, a única via de acesso ao poder, haja vista a recente eleição de Michel Martelly, nas eleições presidenciais de 2011. O poder do carisma de Sweet Micky venceu o discurso de modernização do Estado de Mirlande Manigat, Vice-Reitora da Université Quisqueya, em Porto Príncipe. O caráter do carisma é frágil e cheio de condicionalidades, tal como é a pertença à nação haitiana. Ser nèg e ser carismático obedecem a estruturas similares de sustentação. Não são representação absolutas. Pelo contrário, são testadas e reinventadas cotidianamente. A dinâmica destas identidades cria um núcleo de sentido para a organização social dos lugares das coisas e das pessoas no Haiti, fazendo-nos supor que estruturalmente a fluidez da política, tal como é a do carisma e da categoria nèg conformam o devir da nação e da política no Haiti. Nada é essencial, perene, mas passa por crivos simbólicos que repousam na utopia $v u d u$ à espera de um sentido divino para a nação e para a política. A raiz desta qualidade sobrenatural é a mesa característica do líder carismático. Esta indissociação entre liderança política e liderança carismática torna o cenário político haitiano condicionado à existência de líderes com qualidades sobrenaturais e extracotidiana. Investigar esta correlação de sentidos frente as proposições de Weber podem alimentar uma série de investigações acerca da origem da força política em Estados frágeis e em termos teóricos, aprofundar o debate acerca da natureza transitória da dominação carismática.

\section{Referências}

ANDERSON, Benedict. Nação e consciência nacional. São Paulo: Àtica, 1991.

ARISTIDE, Jean Bertrand. Todo homem é um homem. São Paulo: Paz e Terra, 1995.

CÂMARA, Irene Pessoa de Lima. Em nome da democracia: a OEA e a crise Haitiana 1991-1994. Tese (Doutorado)Instituto Rio Branco. Brasília: FUNAG, 1996.

CASIMIR, Jean. La culture opprimée. Port-au-Price: Imprimerie Media, 2001.

CASIMIR, Jean. Pa Blye, 1804, Souviens - toi de 1804. Port-au-Prince : Imprimerie Lakay, 2004.

CASIMIR, Jean. Libète, egalite sou wout fratènite. Portau-Prince: Presses Nationales d' Haïti, 2005.

CASIMIR, Jean. Haïti et ses élites: L' interminable dialogue de sourds. Port-au-Price: Université d' État d' Haïti, 2009.

CÉSAIRE, Aimé. Toussaint Louverture. Habana: Instituto del Libro, 1967.

DIEDERICH, Bernard; AL BURT. Papa Doc et Les Tontons Macoutes. Port-au-Prince: Imprimerie Henri Deschamps, 1986.

FANON, Frantz. Pele negra, máscaras brancas. Rio de Janeiro: Fator, 1983.

FANON, Franz. Los Condenados de la Tierra. México: Fondo de Cultura Económica, 2001.

FERRO, Marc. Le Livre Noir Du Colonialism. Paris: Robert Laffont, 2003.

THE FUND FOR PEACE. Disponível em: <www. fundforpeace.org $>$. Acesso em: 15 out 2012.

GEERTZ, Clifford. "Do ponto de vista dos nativos: a natureza do entendimento antropológico”. In: . O saber local: novos ensaios em antropologia interpretativa. Petrópolis: Vozes, 1997. p. 85-107.

HENRY, Paget. Caliban's reason: introducing afrocaribbean philosophy. Nova Iorque: Routledge, 2000

HOETINK, Harry. Santo Domingo y el Caribe: ensayos sobre historia y sociedad. Santo Domingo: Fundación Cultural Dominicana, 1994.

HOETINK, Harry. Caribbean race relations: a study of two variants. London: Oxford University Press, 1967. 
HOFFMAN, Leon-François. "Slavery and race in haitian letters”. Caribbean Review, v. 9, n.2, p. 28-32, 1980.

JAMES, C. L. R. Os jacobinos negros. São Paulo: Boitempo, 2000.

LE NOUVELLISTE. Disponível em: <http://www. lenouvelliste.com/>. Acesso em: 23 set 2012.

MANIGAT, Mirlande. "Los derechos humanos en la constitución haitiana de 1987” In: TEJEDA, Eddy (Ed.) El derecho a una vida digna. Santo Domingo: FLACSO, 2002.

MANIGAT, Leslie. L'Amerique Latine au xxè siecle: 18891929. Paris: Richelieu, 1973.

MARRERO ARISTY, Ramón. República Dominicana: origen y destino del pueblo cristiano más antiguo de la América. Trujillo: Del Caribe, 1957.

MURRAY, Gerald F. "Bon-Dieu e os ritos de passagem no Haiti rural: determinantes estruturais da teologia e dos rituais pós-coloniais" Estudos Afro-Asiáticos, n. 19, p. 5-28, 1990.

NICHOLLS, David. From dessalines to duvalier: race, colour and national independence in Haiti. New Brunwick: Rutgers Univ. Press, 2000.

ORGANIZAÇÃO DAS NAÇÕES UNIDAS. Rádio das Nações Unidas. Disponível em: < http://radio.un.org/ por/print all.asp? NewsDate $=11 / 6 / 2006 \& \mathrm{fID}=1>$. Acesso em: 18 ago. 2012.

PIERRE-CHARLES, Gerard. Haiti: crise do Estado e intervenção. Revista teoria e debate, São Paulo: n. 59, , agoset., 2004. Disponível em: http://www.fpabramo.org. br/o-que-fazemos/editora/teoria-e-debate/edicoesanteriores/internacional-haiti-crise-do-estado-e-inter. Acesso em: 8 fev. 2012.

PIERRE-CHARLES, Gerard. Radiographie d'une dictature. Montreal: Nouvelle Optique, 1973.

PONGNON, Vogly Nahum. Election haitienne: présidentielles de novembre 2010. Brasília: Revista Universitas: relações internacionais, v. 8, n.. 2, 2010.

PRICE-MARS, Jean. Así habló el tío. Santo Domingo: Manatí, 2000.

PRICE-MARS, Jean. La vocation de l'elite. Port au Prince: Presses Nationales, 2001.

RÁDIO METROPOLE HAITI. Disponível em: <http:// www.metropolehaiti.com/>. Acesso em: 24 set 2012.
RODRÍGUEZ DEMORIZI, Emilio (Ed.) Cesión de santo domingo a Francia. Trujillo: Archivo General de la Nación, 1958.

RODRÍGUEZ DEMORIZI, Emilio. Invasiones haitianas de 1801, 1805 y 1822. Trujillo: Academia Dominicana de la Historia, 1955.

RODRÍGUEZ DEMORIZI, Emilio. La era de Francia en Santo Domingo. Trujillo: Academia Dominicana de la Historia, 1955.

ROSA, Renata de Melo. "A noblesse haitiana nos duzentos anos do império negro" In: CABRERA, Olga; ALMEIDA, Jaime (Org). Caribe: sintonias e dissonâncias. Goiânia: UFG, 2004.

ROSA, Renata de Melo. "Haiti e os projetos de desenvolvimento: entre o isolamento e a ocidentalização" In: _. A construção da paz no Oriente Médio e Haiti. Brasília: FUNAG, 2011.

ROSA, Renata de Melo. "O Brasil e a não-indiferença à crise haitiana: solidariedade ou retóricas do discurso? Brasília: Revista Universitas: relações internacionais, v. 9, n. 1, p. 487-509, 2011.

SILIÉ, Rubén. "Población y esclavitud en Santo Domingo, en el Siglo XVIII", Revista Investigación y Ciencia, Santo Domigo/RD: Universidad APEC, Año 1, n. 1, 1986.

SILIÉ, Rubén. "Esclavege et prejuge de coleur en Republique Dominicaine", Conjonction Revue FrancoHaitienne: Port-au-Prince, n. 147, 1980.

SILIÉ, Rubén; INOA, Orlando; ANTONIN, Arnold (Ed.) La República Dominicana y Haití frente al futuro. Santo Domingo: FLACSO, 1998.

SILIÉ, Rubén; SEGURA, Carlos; DORE, Carlos Cabral (Ed.). La nueva inmigración haitiana. Santo Domingo: FLACSO, 2002.

SMARTH, Rosny. "Crise, movimento popular, intervenção estrangeira e a presença da América Latina e do Brasil no Haiti”. Brasília: Revista Universitas: relações internacionais, v. 8, n. 1, p. 177-188, 2010.

SMARTH, Rosny. "Intervenções estrangeiras e a presença da América Latina e do Brasil no Haiti". Revista Universitas: relações internacionais, Brasília, v. 8, n. 1, p. 189-200, 2010.

THOMAZ, Omar Ribeiro. "O terremoto no Haiti, o mundo dos brancos e o Lougawou". Novos estudos CEBRAP, São Paulo, n. 86, p. 23-39, mar. 2010. 
TROUILLOT, Michel-Rolph. "The Caribbean Region: an open frontier in anthropological theory”. Annual review of anthropology, Palo Alto, CA: v. 21, p. 19-42, 1992.

WEBER, Max. Economia e sociedade. Brasília: UnB, 1994.
WOODWARD, Susan. Estados falidos: o peso das palavras. Disponível em: <http://www.enjeux-internationaux.org/ articles/num11/pt/estados.htm>. Acesso em: 16 maio 2011. 